
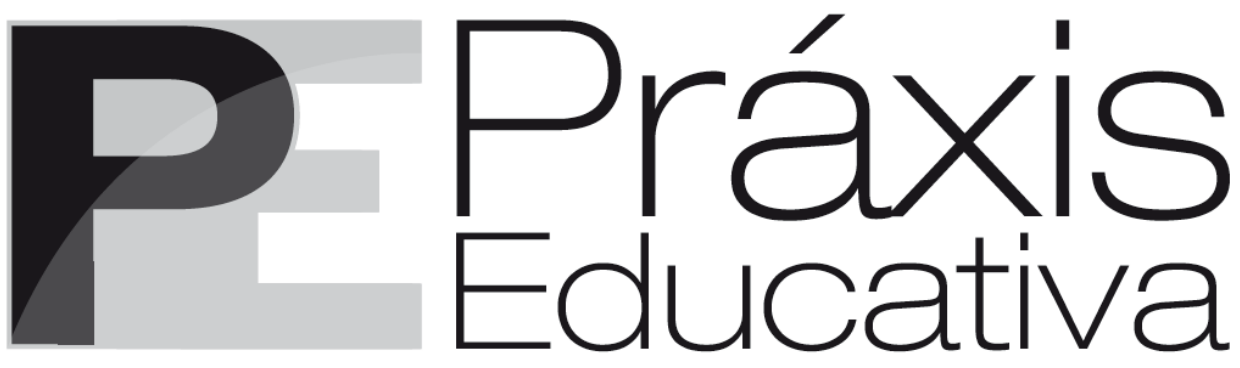

ISSN 1809-4309 (Versão online) DOI: 10.5212/PraxEduc.v.11i3.0004

\title{
Políticas de currículo e avaliação para a docência no espaço Iberoamericano
}

\section{Curriculum policies and teaching evaluation in the Ibero-American context}

\author{
Políticas de currículo y evaluación para la docencia en el espacio \\ Iberoamericano
}

Rosanne Evangelista Dias*

\begin{abstract}
Resumo: A docência tem assumido centralidade nos discursos Iberoamericanos para a educação básica, de modo a atribuir, privilegiadamente, ao trabalho docente a garantia do êxito escolar dos discentes e, consequentemente, o alcance da qualidade da educação. A partir de tais discursos, textos políticos vêm defendendo a produção de políticas de avaliação na tentativa de controlar os currículos da formação (inicial e continuada) e a atuação docente. Neste artigo, orientado teórico-metodologicamente pela Teoria do Discurso de Ernesto Laclau e Chantal Mouffe analiso os processos de articulação discursiva presentes nos textos da Organização dos Estados Iberoamericanos - OEI e da UNESCO, destacando o significante desempenho como foco da avaliação. $\mathrm{Na}$ análise dos discursos para a avaliação da formação e do trabalho docente estabelecida como meta para a região Iberoamericana, tendo como foco o desempenho profissional, as competências assumem importância como modelo de organização curricular. Concluo que as tentativas de controle sobre a comunidade profissional docente na sua formação e trabalho projetam novos papéis para o professor marcados pela responsabilização.
\end{abstract}

Palavras-chave: Políticas de currículo. Avaliação. Docência.

\begin{abstract}
Teaching has become a central issue in the Ibero-American discourses for basic education, in order to attribute, as a privilege, to the teaching work the guarantee of students' school success and, consequently, reach quality in education. From such discourses, the policy texts have defended the production of evaluation policies aiming at controlling the curriculums of teaching education (initial and continuous development) and action. In this paper, which is theoretically and methodologically guided by Ernesto Laclau's and Chantal Mouffe's Discourse Theory, I analyze the processes of discourse articulation present in the texts by Organização dos Estados Iberoamericanos - OEI (Ibero-American States Organization) and UNESCO (United Nations Educational, Scientific and Cultural Organization), highlighting the significant performance as the focus of evaluation. In the analysis of discourses regarding teachers' education and work established as a target for the Ibero-American region, with focus on the professional performance, the competences gain importance as a model of curricular organization. I conclude pointing out that the attempts to control the teaching professional community regarding their education and work assign new roles, marked by accountability, to the teachers.
\end{abstract}

Keywords: Curriculum policy. Evaluation. Teaching.

\footnotetext{
* Professora da Faculdade de Educação e do Programa de Pós-Graduação em Educação (PROPED) da Universidade do Estado do Rio de Janeiro (UERJ). E-mail: <rosanne_dias@uol.com.br>.
}

Práxis Educativa, Ponta Grossa, p. 590-604, v. 11, n. 3, set./dez. 2016 Disponível em: < http://www.revistas2.uepg.br/index.php/praxiseducativa > 
Resumen: La docencia ha asumido centralidad en los discursos Iberoamericanos para la enseñanza básica como forma de atribuir privilegios al trabajo docente y garantizar éxito escolar de los dicentes y, consecuentemente, atingir da cualidad en la educación. A partir de estos discursos, textos políticos defienden la producción de políticas de evaluación en el intento de controlar los currículos de la formación (inicial y continuada) y la actuación docente. En este artículo, orientado por la teoría y metodología de la Teoría del Discurso de Ernesto Laclau y Chantal Mouffe analizo los procesos de articulación discursiva presentes en los textos de la Organización de los Estados Iberoamericanos - OEI y de UNESCO, destacando el significante desempeño como foco de la evaluación. En el análisis de los discursos, para la evaluación de la formación y del trabajo docente establecida como meta para la región Iberoamericana, teniendo como foco el desempeño profesional, las competencias asumen importancia como modelo de organización curricular. Concluyo que los intentos de control sobre la comunidad profesional docente en su formación y trabajo proyectan nuevos papeles para el profesor marcados por la responsabilidad.

Palabras clave: Políticas de currículo. Evaluación. Docencia.

\section{Introdução}

Em muitos momentos da história curricular, a questão da docência assumiu centralidade nos discursos que defendiam a qualidade da educação. Diferentes estratégias foram delineadas em diferentes países do mundo tencionando a busca por um "perfil" docente que reunisse as características de um "bom professor". Não podemos negar a importância do profissional docente no desenvolvimento da educação, mas não podemos atribuir apenas à figura do professor a responsabilidade pelo êxito das políticas educacionais. Muitos outros fatores de âmbito social, político, econômico e cultural são importantes nesse processo e podemos notar que o discurso que busca infundir na figura do professor a responsabilidade pelos resultados que garantem a qualidade na educação acaba por projetar novos papéis para a docência em um cenário de muitas incertezas.

Atualmente, podemos verificar em discursos de organismos internacionais da região Iberoamericana o foco no que constitui o "bom professor" a partir do delineamento de políticas de avaliação docente exploradas nas dimensões da formação e do trabalho docente. Podemos sintetizar em linhas mestras que se projetam na constituição de políticas curriculares de formação de professores, os seguintes aspectos: a) as relações entre o desempenho do professor e do aluno; b) a profissionalização como principal eixo da formação; c) a prática como base para a organização das competências; d) a construção de um perfil profissional; e, e) o estabelecimento de uma cultura da avaliação. Todos os aspectos apontados articulam-se em uma cadeia de equivalência que pretende defender o discurso da qualidade da educação a partir da docência em estratégias de formação e avaliação. Desse modo, a avaliação se faz presente como recurso inerente à profissionalização e ao controle da qualidade da educação.

Neste artigo ${ }^{1}$, analiso discursos que vêm sendo produzidos e propagados na região Iberoamericana em torno da avaliação da formação e do trabalho docente. Nesses discursos, concepções sobre modelos curriculares integrados se fazem presentes na defesa de um novo modo de ensinar e aprender. Os discursos nos textos políticos analisados se caracterizam por modos distintos na sua produção e autoria. Parte deles envolve discursos produzidos por chefes de Estado representantes da pasta da Educação dos países Iberoamericanos. Outra dimensão envolve os discursos produzidos por importantes lideranças no campo da formação de

\footnotetext{
1 Artigo derivado da pesquisa "Discursos nas políticas de currículo para a formação de professores no espaço Iberoamericano", financiada pelo Conselho Nacional de Desenvolvimento Científico e Tecnológico - CNPq e pela Fundação Carlos Chagas de Amparo à Pesquisa do Estado do Rio de Janeiro - FAPERJ.
}

Práxis Educativa, Ponta Grossa, p. 590-604, v. 11, n. 3, set./dez. 2016 Disponível em: <http://www.revistas2.uepg.br/index.php/praxiseducativa> 
professores, difundidos pelas publicações dos mesmos organismos internacionais. Para esta análise selecionei textos políticos de organismos internacionais que buscam no seu papel catalisador de políticas curriculares (DIAS; LÓPEZ, 2006), produzir consensos possíveis em torno da docência e suas relações com a qualidade da educação para a região Iberoamericana. Dentre os textos analisados, destaco os da Organização dos Estados Iberoamericanos para a Educação, a Ciência e a Cultura - OEI e da Organização das Nações Unidas para a Educação, a Ciência e a Cultura - UNESCO, em especial sua Oficina Regional para a América Latina e o Caribe - OREALC, sediada em Santiago, no Chile. Os textos analisados foram produzidos no período de 2001 a 2013.

Como marco temporal para a seleção dos textos políticos, elegi o Relatório Jacques Delors da UNESCO no Brasil, uma vez que a produção que está em pauta está sendo produzida nos marcos da Conferência de Educação para Todos, em Jomtien. Foram selecionados os seguintes documentos: Relatório Jacques Delors (UNESCO, 2001), Antecedentes y Criterios para la Elaboración de Políticas Docentes en América Latina y el Caribe (UNESCO, 2012), Metas Educativas 2021 (OEI, 2010), Miradas sobre la Educación en Iberomerica (OEI, 2011) e Miradas sobre la Educación en Iberoamérica. Desarrollo profesional docente y mejora de la educación (OEI, 2013). Reconheço os limites na escolha dos textos políticos analisados considerando a diversidade desse material. Ressalto ainda que a análise assumida neste artigo considera o caráter contingente e precário desses textos políticos como representativos de uma região. Com isso, não pretendo assumir que tais discursos representam a totalidade do pensamento sobre política curricular dos países que dela fazem parte. Antes, representam parcialmente as proposições que se fazem presentes na articulação da política, como nos faz compreender a teoria do discurso de Laclau $(1996,2005)$.

A teoria do discurso de Ernesto Laclau e Chantal Mouffe nos orienta teóricometodologicamente neste artigo para a análise dos discursos produzidos nos textos políticos selecionados. Assim, entendo discurso como "uma prática articulatória que constitui e organiza as relações sociais" (LACLAU; MOUFFE, 2015, p. 167). Ao analisar os processos de articulação discursiva busco compreender como as propostas de avaliação articulam aspectos da política de currículo e da docência na defesa de modos de ser e exercer o magistério estabelecendo, cada vez mais, correspondência entre o desempenho do professor e o de seus alunos e orientando políticas de currículo em diferentes escalas. Como as concepções de avaliação para a docência são articuladas discursivamente nos textos analisados e como pretendem fixar uma suposta ideia de desempenho como algo a ser mensurado e verificado para um possível controle da qualidade da educação, são aspectos que também nos orientam nesta análise.

Tendo como foco os processos de articulação discursiva, desenvolvo na primeira seção como os discursos pela centralidade da docência vêm sendo produzidos nas políticas de currículo, considerando os diferentes sentidos produzidos nos textos políticos Iberoamericanos. $\mathrm{Na}$ segunda seção, analiso os processos de avaliação defendidos discursivamente no espaço Iberoamericano, destacando o significante desempenho e suas relações com aspectos da formação curricular e do trabalho docente. Encerro com considerações iniciais sobre a projeção de perfis profissionais docentes a partir da avaliação como pretensão de um controle do conteúdo da formação e da atuação docente, problematizando diferentes discursos em disputa nos organismos internacionais, entendendo que a construção de um consenso possível (MOUFFE, 1996) constitui em uma tarefa a ser atingida na região. 


\section{Centralidade da docência em discursos Iberoamericanos}

Ao longo das últimas décadas, os discursos das reformas educacionais que têm se dirigido ao currículo vêm apontando para a centralidade do professor na construção de suas agendas políticas. Em parte, essa centralidade está voltada para a importância do professor como agente das reformas, aquele de quem se espera o compromisso em empreender esforços para que elas sejam concretizadas e bem sucedidas. O conceito de reforma empregado neste artigo apoia-se em Popkewitz (1997) e aponta para a perspectiva de intervenção de públicos investidos de conhecimento e poder em relações sociais nas arenas políticas em que ocorre.

Inicio com a produção da UNESCO a partir do Relatório Delors ${ }^{2}$ (2001), também conhecido pelo título "Educação, um tesouro a descobrir", marcado por uma complexa rede de influências políticas, "um texto que projeta princípios para as políticas curriculares e que tem influenciado a produção de políticas em variados países do mundo" (DIAS; LÓPEZ, 2006, p.55). O Relatório Delors é exemplar para verificar o papel de influência na produção de políticas em diferentes escalas como apontado por Ball $(1994,1998)$ e Ball e Bowe (1998) na abordagem do ciclo de políticas para a análise das reformas educativas. No contexto de influência, os organismos internacionais atuam como comunidades epistêmicas, constituídos por um corpo de especialistas na área de políticas públicas em torno de uma agenda global para auxiliar no processo de tomada de decisões (ANTONIADES, 2003). Desse modo, as ideias produzidas e difundidas pela UNESCO têm como finalidade a produção de políticas de currículo, entre outras da educação, em diferentes Estados-Nação.

A docência, no Relatório Delors (2001), é destacada no cenário de tensões do mundo, apresentada no seguinte contexto

Encaramos o próximo século como um tempo em que, por toda parte, indivíduos e poderes públicos considerarão a busca do conhecimento, não apenas como meio para alcançar um fim, mas como fim em si mesmo. Todos vão ser encorajados a aproveitar as ocasiões de aprender que se lhes oferecem ao longo da vida e terão possibilidades de o fazer. $O$ que significa que se espera muito dos professores, que se lhes irá exigir muito, pois depende deles, em grande parte, a concretização desta aspiração. (p. 152).

É por isso que são enormes as responsabilidades dos professores a quem cabe formar o caráter e o espírito das novas gerações. A aposta é alta e põe em primeiro plano os valores morais adquiridos na infância e ao longo da vida. (p. 153).

Às responsabilidades atribuídas ao professor nesse complexo cenário global apontado no documento, associam-se para a melhoria da qualidade da educação a necessidade de

(...) antes de mais nada, melhorar o recrutamento, a formação, o estatuto social e as condições de trabalho dos professores, pois estes só poderão responder ao que deles se espera se possuírem os conhecimentos e as competências, as qualidades pessoais, as possibilidades profissionais e a motivação requeridas. (DELORS, 2001, p. 153).

Entre os discursos pela centralidade dos professores no Relatório Delors podemos destacar a de que eles "desempenham um papel muito influente em vários domínios" (p. 156) e de que "nenhuma reforma da educação teve êxito contra ou sem os professores" (p. 156). Nas passagens citadas, notamos a força atribuída aos professores no exercício de seu trabalho e como podem exercer o poder nas atividades que realizam, o que reforça a importância que a docência

2 O Relatório Delors resultou do trabalho de três anos e meio de uma Comissão Internacional sobre Educação para o século XXI, oriunda de uma Conferência Geral da Unesco em 1991, presidida por Jacques Delors. A produção do Relatório Delors foi um dos desdobramentos da Conferência Mundial Sobre Educação para Todos, realizada em Jomtien, na Tailândia, em 1990. 
possui potencialmente para que as propostas curriculares sejam de fato assumidas. Assim, a responsabilidade do professor em relação à qualidade da educação atinge expectativas sociais, como podemos ver no Relatório Delors (2001), ao afirmar que "os alunos e a sociedade no seu conjunto têm o direito de esperar deles que cumpram a sua missão com dedicação e com um profundo sentido de responsabilidade" (p. 166). Podemos identificar no protagonismo docente a ambivalência no papel do professor, como apontado em trabalhos anteriores (DIAS, 2009, 2013) marcado tanto pela importância do caráter criador e autônomo do seu trabalho como na performatividade no trabalho docente ao exigir resultados no desempenho dos alunos como critério exclusivo de mérito de sua atuação na educação.

A centralidade do professor, assumida após as reformas ocorridas nos currículos da escola básica, põe em questão o currículo da formação dos professores, seja inicial ou continuada, privilegiando a última em razão de esta articular-se com a flexibilidade exigida em processos de formação em que se defende a capacidade de adaptação dos trabalhadores às mudanças na sociedade do conhecimento, assumindo desse modo uma perspectiva de "aprender a aprender". Pretende-se projetar o trabalho do professor desde sua carreira até a sua prática cotidiana a partir de concepções que se anunciam como novas bases profissionais, situadas no saber-fazer.

Em outro texto político da UNESCO (2012) que se apresenta como um estado da arte para orientar políticas docentes para a América Latina e o Caribe, "Antecedentes y Criterios para la Elaboración de Políticas Docentes en América Latina y el Caribe, produzido a partir da colaboração de importantes lideranças acadêmicas ${ }^{3}$, sindicais e governamentais no campo da formação de professores na região. Mais uma vez, a força da comunidade epistêmica se faz presente na apresentação do texto político, expressando como as relações de conhecimento e poder (ANTONIADES, 2003; LOPES, DIAS, ABREU, 2011) se fazem presentes na produção da política curricular. Corroborando o Relatório Delors, a UNESCO (2012) afirma que "La evidencia disponible apunta a que los maestros son la clave para el buen desempeño de alumnos, escuelas y sistemas" (PISA, 2009; OCDE, 2009; MOURSHED, CHIJIOKE Y BARBER, 2010 apud UNESCO, 2012, p. 59), com ênfase em processos que valorizam a prática na escola básica, destacando programas de formação continuada com diferentes constituições.

Na tentativa de valorização da docência para a região Latino-Americana e do Caribe, o texto aponta para a necessidade de "atrair e reter bons docentes" para a carreira de modo a viabilizar uma educação de qualidade e destaca o que consideram um paradoxo para as políticas dirigidas à docência na região.

si bien existe unanimidad sobre su importancia y centralidad, cuestión que declara prácticamente todo discurso de políticas en el sector, en los hechos, los cursos de acción efectiva respecto a los docentes no ocupan la posición estratégica en los diseños de políticas. Esto se debe a múltiples razones, que son las que un discernimiento sobre la nueva agenda debe discutir e intentar resolver. (UNESCO, 2012, p. 97).

Como diagnóstico da não centralidade alcançada nas políticas dirigidas à docência, a UNESCO (2012) aponta como fatores o "alto costo cuando se proponen afectar al conjunto de la docencia, poco visibles para el público en su implementación, políticamente complejas, y de mediano y largo plazo en el logro de los efectos buscados" (p. 97), constituindo-se em políticas com alto grau de dificuldade, segundo os termos do texto político do organismo internacional. O texto ainda vai problematizar a questão do paradoxo ao criticar o que identificamos como

\footnotetext{
3 Os especialistas aos quais se refere o texto foram designados para o desenvolvimento das seguintes temáticas: formação inicial (Beatrice Ávalos, Chile); formação e desenvolvimento profissional contínuo (Sylvia Ortega, México); carreira docente (Denise Vaillant, Uruguay); organizações docentes (Mariano Palamidessi, Argentina); e institucionalização de políticas docentes (Simón Schwartzman, Brasil).
}

Práxis Educativa, Ponta Grossa, p. 590-604, v. 11, n. 3, set./dez. 2016 Disponível em: <http://www.revistas2.uepg.br/index.php/praxiseducativa> 
discurso em defesa da correspondência entre desempenho dos alunos e a docência, ao ser considerada a precariedade na qual ainda se encontra a região no que tange à valorização da carreira docente

\begin{abstract}
es que si se toma como verdadera la afirmación de que el sistema educativo y los aprendizajes que logre y distribuya socialmente tendrán la calidad correspondiente a la calidad de sus docentes (Barber y Mourshed, 2007), estos profesionales, su formación y las condiciones en que trabajen debieran ser el verdadero centro de los esfuerzos públicos en educación. (UNESCO, 2012, p. 97).
\end{abstract}

Assumir o discurso pela centralidade da docência nas políticas curriculares envolve o reconhecimento da relevância do trabalho docente, como afirma o texto da UNESCO (2012), "como uno de los factores decisivos para una educación de calidad y equitativa representa un desafío enorme para la profesión y para quienes inciden en su fortalecimiento" (p. 111-112). Nesse mesmo texto, busca-se reconhecer a necessidade de definir "una identidad professional basada en lo que debe saber y poder hacer un docente, en general y de acuerdo a su respectiva área de especialización (p. 112). O discurso caminha na direção de uma autorregulação dos professores para que possam vir a "definir normas éticas y de desempeño profesional que orienten y regulen su quehacer, cuestión sobre la cual no se han encontrado mayores evidencias en la Región y que debiera ser un norte de su quehacer y desarrollo futuros" (p. 113). Mas a autorregulação vem acompanhada de mecanismos de regulação externa, via sistemas de avaliação docente como veremos na próxima seção.

Nos textos políticos da OEI, respectivamente Miradas (2011) e Metas (2010) nos debruçamos sobre a Meta Geral 8: Fortalecer a profissão docente, que na Meta Específica 20: Mejorar la formación inicial del professorado de primaria y de secundaria que se desdobra em quatro indicadores que envolvem titulação, formação contínua, carreira docente para os vinte e um países membros. Tais metas, estabelecidas para serem atingidas até 2021, o Ano da Geração dos Bicentenários de Independência da maior parte dos países da região Iberoamericana, têm entre os objetivos poder "contar con un profesorado con las competencias necesarias para influir positivamente en el rendimiento de los estudiantes" (OEI, 2011, p. 222), "Si se piensa en la calidad de la educación de un país, es inevitable hacerlo en relación con la calidad de su profesorado" (OEI, 2010, p. 74) e, ainda, na metáfora da moeda "el desarrollo profesional docente y la mejora de la escuela constituyen las dos caras de una misma moneda" (OEI, 2010, p. 134), fortalecendo a ideia de correspondência entre docência e desempenho discente como a UNESCO apresenta nos textos políticos destacados. Em outros enunciados podemos verificar o fortalecimento da ideia de correspondência entre desempenho do aluno e docência ao se afirmar

Cuanto mejor preparación inicial se garantice a los docentes de un país, mayores serán sus capacidades y recursos pedagógicos para interaccionar con sus alumnos, crear ambientes adecuados en el aula y conducir procesos de aprendizaje exitosos. (OEI, 2011, p. 227).

Una premisa central de las reformas educativas que buscan una mayor calidad en la enseñanza es que esta solo es posible si mejora sustancialmente la calidad profesional de quienes enseñan, y de ahí que la mayoría de los sistemas educativos ofrezca a su profesorado programas de formación con el objetivo de mejorar la práctica docente y asegurar el éxito de los objetivos educativos. (OEI, 2011, p. 233).

La formación de los maestros en las competencias necesarias para enseñar a las nuevas generaciones, tal vez sea la dimensión más importante para la mejora de la calidad de la enseñanza y de los aprendizajes de los alumnos. (OEI, 2010, p. 135-136).

$\mathrm{Na}$ defesa que se faz nos enunciados pela correspondência entre desempenho discente e docência, o documento Miradas (OEI, 2011) se apoia "en diversas investigaciones internacionales

Práxis Educativa, Ponta Grossa, p. 590-604, v. 11, n. 3, set./dez. 2016 Disponível em: <http://www.revistas2.uepg.br/index.php/praxiseducativa> 
que señalan la importante influencia de los docentes para la calidad de los sistemas educativos" (p. 240). Contudo, o próprio texto político ressalta que "los resultados de los estudios no han sido concluyentes respecto a cuáles son concretamente los factores relacionados con la efectividad del profesorado" (p.240), o que revela pouca consistência na defesa que vem sendo promovida em torno da responsabilização dos professores pelos resultados acadêmicos de seus alunos nas políticas curriculares de diferentes países da região, incluindo o Brasil.

A centralidade na docência produzida discursivamente nos textos políticos analisados, problematiza uma série de questões que envolvem a heterogeneidade da docência na Região e as particularidades dos problemas em cada pais Iberoamericano, tanto no que se refere aos diferentes processos de formação como nas condições de trabalho singulares que são identificadas nos textos políticos, em especial, no texto político Miradas sobre la Educacion em Iberoamérica - Desarrollo profesional docente y mejora de laeducación (OEI, 2013). Mesmo reconhecendo uma série de aspectos que são importantes para o desenvolvimento da profissão docente apresentados nos textos políticos, entendo que o foco no professor projeta para a sua atuação um papel de agente garantidor da qualidade e êxito da educação. Esse novo papel, articula-se discursivamente com a necessidade de normatizações da formação e do trabalho docente promovendo processos de regulação marcados por avaliações de desempenho e pela cultura da performatividade.

\section{Discursos da avaliação na formação e trabalho docente: o foco no desempenho}

Embora todos os textos analisados neste artigo tenham abordado o papel da avaliação docente no cenário da educação Iberoamericana, em dois textos políticos, mais particularmente, o tema assume aprofundamento: Antecedentes y Criterios para la Elaboración de Políticas Docentes en América Latina y el Caribe (UNESCO, 2012) e Miradas sobre la Educación en Iberoamérica - Desarrollo profesional docente y mejora de la educación (OEI, 2013).

Ainda são poucas as experiências na América Latina e no Caribe assim como nos países Iberoamericanos sobre a avaliação docente. $\mathrm{Na}$ apresentação do tema, a UNESCO e OEI em seus textos apontam a insuficiência nas informações dos países sobre as políticas para o desenvolvimento dessas políticas. O que podemos destacar sobre os dados é que predominam avaliações vinculadas à titulação do professor e ao desenvolvimento da carreira docente, repercutindo em vantagens salariais e em alguns países, avaliações realizadas por inspeção, Ministérios da Educação, Institutos de Avaliação da Educação, Conselhos Escolares, entre outros. Em alguns países as avaliações são periódicas, enquanto em outros, não. Os instrumentos podem ser provas para os professores para acesso a profissão (concurso) ou para permanência, sistemas de observação e matérias desenvolvidos para o trabalho e pagamento por mérito, por vezes, como retribuição à obtenção de titulação ou nível de formação, ou em resposta às metas atingidas na avaliação discente, como desenvolvido pela Secretaria de Educação do Município do Rio de Janeiro, com o $14^{\circ}$ salário. Há, portanto, uma variedade de experiências de avaliação docente, sendo algumas externas e combinadas com a avaliação dos alunos (modelo de valor agregado) e outras não, focalizadas em processos do trabalho docente nas instituições escolares, voltadas à localidade. Em alguns países, a avaliação docente é obrigatória e em outros, voluntária. No primeiro caso, geralmente associada ao ingresso na carreira ou para avaliação da continuidade nela (Peru, Equador, Chile) no segundo, para ascensão em outros cargos na carreira, como gestor ou pesquisador (Brasil, Guatemala, Nicarágua). As informações destacadas a partir dos textos 
políticos da UNESCO (2012) e OEI (2013) dão conta da pluralidade de propostas presentes na região ${ }^{4}$.

Nos textos analisados, o discurso da avaliação se faz presente no desenvolvimento da docência seja na formação ou na atuação. Nela, o desempenho é o foco privilegiado, enfatizando a formação continuada como estratégia que mais se coaduna com a ideia do "aprender a aprender". Nos textos da UNESCO a avaliação é assumida como um "tema prioritário" e conflituoso, em especial entre autoridades educativas e sindicatos/associações de classe. A UNESCO (2012) sintetiza em seu documento, entre as questões tensionadas no debate da avaliação docente: a) objeto da avaliação; b) os atores que avaliam; c) os critérios para avaliação; d) os instrumentos e procedimentos; e, e) a relação entre os resultados e os incentivos. Se a UNESCO (2012) "reconoce que la evaluación del desempeño docente es un tema altamente conflitivo" (p. 88) por incorporar interesses, opiniões e concepções antagônicas, por que a meta de avaliar professores tem sido importante para o desenvolvimento das políticas atuais na região Iberoamericana? Por que, mesmo reconhecendo o modelo finlandês de educação como de qualidade sem qualquer avaliação externa de seus professores (nem debate sobre a possibilidade de ela vir a ser concretizada no país), pois na Finlândia existe confiança na formação e no trabalho do professor, como o próprio texto da UNESCO aponta, o modelo praticado nesse país não é ressaltado como experiência a ser considerada pelos países da região? Sobre o discurso da avaliação a partir do exemplo da Finlândia, destaco um excerto da OEI na tentativa de desconstrução desse mesmo discurso

[...] tener un buen sistema de evaluación de los maestros puede contribuir a mejorar los resultados de los alumnos, sin olvidar que la evaluación por si misma no produce mejora alguna, aunque sí puede aportar información sobre la situación prevaleciente y, en el mejor de los casos, sobre los obstáculos que se oponen a la calidad y los factores que pueden favorecerla. (OEI, 2013, p. 269).

Estas intervenciones externas han sido fuertemente cuestionadas por muchas organizaciones docentes y por especialistas, ya que ven en ellas un deterioro de la profesionalización docente y una subordinación de las comunidades educativas a instancias técnicas o burocráticas, a veces, externalizadas a diversos agentes privados, cuyas propuestas pueden ser muy descontextualizadas respecto de las necesidades de las escuelas o incluso determinadas por intereses económicos particulares. (UNESCO, 2012, p. 111).

Na centralidade que a docência adquiriu nos discursos das políticas de currículo, a defesa da avaliação do desempenho vem se colocando como uma estratégia que assume protagonismo nos últimos trinta anos. Em parte, como modelo agregado nos termos do texto político da OEI (2013), aos processos de avaliação dos alunos que, em diferentes escalas, têm se apresentado como mecanismo de controle da qualidade da educação, do desempenho ou para a prestação de contas à sociedade.

[...] es bastante clara también la influencia de los sistemas internacionales de evaluación como PISA de la OCDE, SERCE de UNESCO y TIMSS de la IEA ${ }^{5}$, no solamente por los resultados que presentan y su probable influencia sobre los currículos, sino también por el desarrollo de sistemas nacionales de evaluación educativa que han estimulado en

\footnotetext{
4 Para maior detalhamento e aprofundamento dos dados sobre o sistema de avaliação docente na região Iberoamericana, sugiro o acesso ao link: <http://www.oei.es/publicaciones/InformeMiradas2013.pdf>.

5 As siglas dos sistemas internacionais de avaliação significam, respectivamente: PISA (Programa Internacional de Avaliação de Alunos) da OCDE (Organização para a Cooperação e o Desenvolvimento Económico), SERCE (Segundo Estudo Regional Comparativo e Explicativo para avaliação do desempenho dos estudantes na América Latina e no Caribe da OREALC - UNESCO, TIMSS (Estudo Internacional de Tendências em Matemática e Ciências) da IEA-Associação Internacional para a Avaliação do Rendimento em Educação.
}

Práxis Educativa, Ponta Grossa, p. 590-604, v. 11, n. 3, set./dez. 2016 Disponível em: <http://www.revistas2.uepg.br/index.php/praxiseducativa> 
los distintos países. La OCDE, finalmente, ha tenido un papel significativo al difundir buenas prácticas de política educativa a través de las evaluaciones que hace de los sistemas educativos de los países que las solicitan. (UNESCO, 2012, p. 101).

La aplicación de pruebas estandarizadas de rendimiento a grandes muestras de alumnos, o incluso a todos los de ciertos grados, que se ha extendido en muchos países desde la década de 1990, ha llevado a proponer una forma alternativa de valorar o desempeño de los maestros, sin tener que observar a cada uno em el aula ni basearse solo en escolaridad y antigüedad. (OEI, 2013, p. 233).

Com a visibilidade que se pretende na divulgação do produto das avaliações externas dos estudantes e dos professores está em jogo não apenas a prestação de contas para a sociedade, mas o papel do Estado avaliador na divulgação dos resultados que, por vezes, é disseminado intensamente pelas mídias sem maior aprofundamento de aspectos que envolvem os resultados a que se chegou. O gerencialismo acentua os processos de competição entre instituições de educação ao enfatizar o alcance de metas expressos nas respostas aos exames e testes de avaliação externa (OLIVEIRA; JORGE, 2015, HYPOLITO, 2011). A exposição dos resultados da avaliação quando não considera o contexto de complexidade no qual a escola, os alunos e os docentes estão envolvidos, acaba por produzir na sociedade uma desconfiança na educação e nos docentes, figura destacada como fundamental para o alcance da qualidade da educação. Para a UNESCO (2012), deve-se "alcanzar un equilibrio entre la confianza en la labor de los maestros y la responsabilización por su desempeño" (p. 112).

Dos de estas fuerzas son clave. La primera, es un Estado sólido que cuente con una administración pública eficaz que se rija por mecanismos acertados de rendición de cuentas. La segunda es una cultura profesional firmemente arraigada, que comprometa al profesorado y otros partícipes importantes con valores de conducta, estándares altos de idoneidad docente y una orientación al interés público. (UNESCO, 2012, p. 110).

Por outro lado, a avaliação docente também tem sido defendida como mecanismo de controle dos cursos de formação inicial e continuada para aferir qualidade e prestação de contas para a sociedade. Analisando as articulações discursivas nos textos políticos podemos identificar a ambivalência do que se defende como controle que, por vezes, se dirige ao acompanhamento social dos recursos públicos aplicados em demandas sociais também públicas, como a educação em todos os seus níveis e, outras vezes, ao controle que marcou a história curricular no período conhecido por eficiência social. A ambivalência presente nos discursos pela avaliação docente nos textos políticos analisados pode ser verificada nos excertos em que ora se reconhece a singularidade da docência, ora se estabelecem padrões de avaliação como base do aprender e ensinar e ainda, ao enunciar um suposto perfil capaz de agregar e representar uma categoria tão ampla e complexa como a do magistério.

[...] el desarrollo profesional docente puede ser muy diferente en escenarios diversos y debe responder a los contextos y necesidades específicas de las escuelas y sus docentes. (OEI, 2013, p. 159).

Detrás de todo proceso de formación y evaluación existe una apuesta hasta uno o varios modelos de aprender y enseñar, y, por lo tanto, un perfil (o perfiles) de docente que el sistema educativo requiere para alcanzar dichas expectativas, por lo que en la medida en que los países puedan alcanzar acuerdos sobre estos aspectos, dichos procesos podrán estar más clara y lógicamente ordenados. (OEI, 2013, p. 180).

Los esfuerzos realizados por algunos países por elaborar estándares son de gran importancia, no solo porque estos constituyen una referencia clave para el desarrollo profesional y la evaluación del desempeño, sino porque definen una identidad profesional basada en lo que debe saber y poder hacer un docente, em general y de acuerdo a su respectiva área de especialización. (UNESCO, 2012, p. 112).

Práxis Educativa, Ponta Grossa, p. 590-604, v. 11, n. 3, set./dez. 2016 Disponível em: <http://www.revistas2.uepg.br/index.php/praxiseducativa> 
A teoria da eficiência social foi um movimento com presença de teóricos do currículo norte-americanos no início do século XX como Franklin Bobbitt e Werret Charters. Nos anos 1950 assume importância no desenvolvimento da organização do planejamento escolar (Ralph Tyler), a pedagogia dos objetivos e a pedagogia das competências, esta última, especialmente voltada para a formação dos professores. Neste último movimento, podemos verificar uma série de metodologias voltadas para o currículo, tendo como base as competências: Competency - Based Teacher Education - CBTE, Performance-Based Teacher Education - PBTE e Microensino (LOPES; MACEDO, 2011, DIAS; LOPES, 2003). Nessas experiências curriculares, o modelo de competências se coaduna com os exames estandardizados a serem aplicados aos professores, como reconhece a UNESCO (2012).

Podemos sintetizar o movimento da eficiência social voltado para alguns aspectos, buscando relacionar características do passado com as do presente, como: a) a responsabilização da escola e dos agentes que nela trabalham em relação aos resultados que são esperados da instituição pela sociedade; b) a forte vinculação entre o sistema produtivo e o educacional, em especial voltado à flexibilidade e o 'aprender a aprender" para enfrentar as contingências de empregabilidade com vínculos precários; c) a utilização das orientações da psicologia comportamental como base para as experiências educacionais, com ênfase na avaliação do desempenho; e, d) uma supervalorização das técnicas e tecnologias no ensino voltadas à mensuração, entre as mais importantes, presentes também sob novas bases nas políticas curriculares e avaliação.

A influência da eficiência social nos modelos de formação de professores se fez presente desde os anos 1960 nos EUA. Ao longo de quase oito décadas o país desenvolveu o movimento de formação baseado nas competências, cujo principal objetivo foi a formação do professor eficiente para atender às necessidades que estavam postas pela sociedade. Modelos curriculares baseados nas competências e inspirados na teoria da eficiência social tinham como propósito forjar uma formação que tivesse como finalidade a eficácia do professor, com associação estreita entre desempenho do aluno e do docente. Acreditava-se que alunos com bom desempenho escolar possuíam bons professores ou professores eficazes. Nessas investigações sobre a eficácia do professor podiam ser identificados dois tipos de abordagens: um que partia das características pessoais pensadas como sendo as ideais para um professor eficiente e outro que partia da descrição de funções que o professor desempenhava, ou a sua prática, passível de verificação daquilo que o professor concretizava de "modo eficiente, efetivo e econômico" (MAGER; BEACH, 1976: XI).

Enquanto algumas pesquisas sobre o professor eficaz pretendiam conhecer o que ele era, a outras importava saber o que ele fazia. Nas duas perspectivas, o comportamento do professor era o foco principal e, portanto, visava à avaliação do desempenho docente. Encontrar um currículo de formação que pudesse ser consequente no alcance das destrezas esperadas de um professor eficaz passou a ser o objetivo central dessas pesquisas. As destrezas que compunham um curso eram obtidas a partir de estudos nos quais se realizavam descrições das atitudes dos professores eficazes (OLIVA; HENSON, 1989). Entre as décadas de 1960 e 1970 essas pesquisas foram realizadas orientadas por esse pressuposto tendo em vista o estabelecimento da competência do professor, intensificando-se a mensuração do que se pretendia avaliar. Esse período de produção de políticas curriculares com foco na avaliação do desempenho docente no ensino e o desempenho do aluno na aprendizagem foi denominado por Gimeno Sacristán (1989) como modelo processo-produto. Mas esse modo de pensar a formação de professores não ficou preso ao passado e pode ser traduzido em enunciados que destaco no texto da OEI (2013) em defesa de sistemas de avaliação dos docentes que tenham por finalidade definir um bom professor, como em décadas passadas foi almejado.

Práxis Educativa, Ponta Grossa, p. 590-604, v. 11, n. 3, set./dez. 2016 Disponível em: <http://www.revistas2.uepg.br/index.php/praxiseducativa > 
El punto de partida de un sistema de evaluación de docentes es la definición de "buen maestro". La complejidad de la conceptualización de un buen docente hace necesarias dos consideraciones: que la definición de base del sistema de evaluación sea el resultado del consenso más amplio posible de los actores relevantes, y que se incluyan o destaquen las circunstancias del sistema educativo en las que los docentes desempeñan su trabajo. (p. 283).

No desenvolvimento de instrumentos de avaliação docente, a OEI (2013), tomando por base o modelo curricular por competências, sugere:

Punto de partida indispensable para una buena evaluación de docentes es una definición precisa de lo que es un buen docente; solo después habrá que buscar las mejores formas de obtener información sobre le grado en que el trabajo de ciertos maestros reúne o no los rasgos identificados. (OEI, 2013, p. 234).

Cada uno de estos rasgos generales se precisa con diversos grados de detalle, hasta llegar a definiciones operacionales muy precisas, que permiten desarrollar instrumentos de obtención de información al respecto. (OEI, 2013, p. 235).

Como já analisado por Jones e Moore (1993), o modelo curricular das competências assume a orientação da psicologia comportamental ao estabelecer mecanismos de controle de desempenho e a fragmentação das atividades no estabelecimento de habilidades, tendo como perspectiva o alcance de resultados, como podemos observar nos excertos da OEI (2013). A defesa e aceitação do modelo de competências para a avaliação docente tem mais fundamentos metodológicos que conceituais. Jones e Moore (1993) reconhecem o apoio do modelo de competências por aqueles que defendem a produção e o uso de técnicas para a descrição e avaliação de habilidade e desempenho, como afirmação de sua "auto-evidência". Esse modelo, amparado por modos pedagógicos projetados, segundo Bernstein (1998), encontra bastante reforço por parte do Estado por meio de suas agências reguladoras do conhecimento especializado em si, que têm como função "autorizar" e "legitimar" o que e "quem poderá dizer o que realmente 'conta' como uma realização legítima ou permitida do eu" (JONES; MOORE, 1993, p. 396). A necessidade do controle para a informação do quadro docente empobrece e reduz as possibilidades singulares que são constituídas pelos professores nas escolas básicas e demais espaços de formação de alunos dos mais diferentes níveis e modalidades.

$\mathrm{Na}$ defesa pela associação entre a formação de professores e a qualidade da educação, como desenvolvemos na seção anterior, é afirmado que "há que dar mais importância aos resultados da aprendizagem e ao papel desempenhado pelos professores na obtenção dos mesmos" (DELORS, 2001, p. 160). Mas para o alcance de resultados satisfatórios, ou eficazes, nos termos do Relatório Delors argumenta-se pela "existência de um sistema de avaliação e controle que permita diagnosticar e remediar as dificuldades, e em que a inspeção sirva de instrumento para distinguir e encorajar o ensino de qualidade" (DELORS, 2001, p. 165). Mas como outra face da moeda, a avaliação pode conduzir o trabalho docente a determinadas finalidades que estejam mais consoantes com as expectativas de resultado que se pretende obter nas avaliações externas e na visibilidade que ela objetiva alcançar.

Los resultados insatisfactorios y, muchas veces, decrecientes de la calidad de la educación pública, dramatizados por los resultados de las evaluaciones comparativas internacionales, han llevado en muchos países a la creación de sistemas externos que buscan influenciar y conducir las actividades docentes desde afuera. Estos sistemas pueden considerar la evaluación y monitoreo de las actividades de los maestros y los resultados pedagógicos logrados, a través de sistemas externos de evaluación, la sistematización de los contenidos que los estudiantes deben aprender y alteraciones en las carreras docentes, restringiendo la autonomía de los maestros en clases y creando sistemas de estímulos positivos o negativos en función de sus logros, según metas definidas externamente. (UNESCO, 2012, p. 110).

Práxis Educativa, Ponta Grossa, p. 590-604, v. 11, n. 3, set./dez. 2016 Disponível em: <http://www.revistas2.uepg.br/index.php/praxiseducativa> 
Embora o discurso em defesa da avaliação docente seja reafirmado em todos os textos políticos analisados, é possível encontrar deslizamentos discursivos que nos apontam para a precariedade que caracterizam tais sistemas, como no excerto da OEI (2013)

\begin{abstract}
Tener un buen sistema de evaluación de los maestros puede contribuir a mejorar los resultados de los alumnos. Pero conviene resaltar que dichos resultados dependen, en parte, de las condiciones que prevalecen en el hogar y el medio en que vive cada uno, en parte de las escuelas a las que asisten y, también, de los profesores, que constituyen el factor sin duda más importante. Además, debe tenerse em cuenta que la evaluación por sí misma no produce mejora alguna. (p. 279).
\end{abstract}

O significante desempenho, articulado discursivamente com o foco central da avaliação docente nos coloca diante de modelos curriculares que foram exemplares na ênfase da técnica e da mensuração para o desenvolvimento das finalidades educacionais, voltado para a eficácia e eficiência do sistema com base em resultados obtidos nas avaliações, enfatizando o conhecimento instrumental e a prescrição curricular. Nos discursos dos textos políticos analisados corroboro com Lopes (2001) e Macedo (2002) no destaque à dimensão metodológica ou "o como" desenvolver o ensino na educação básica que vem assumindo discursivamente centralidade na região Iberoamericana como sendo a base da avaliação do desempenho docente.

\title{
Considerações finais
}

Como desenvolvido anteriormente, ao eleger determinados textos políticos de uma região a partir de organismos internacionais, reconheço as limitações que tal seleção resulta. Contudo, também considero a necessidade de conhecermos os diferentes discursos que são produzidos e disseminados para a docência que visam a propor currículos e avaliação como forma de controlar a formação e o trabalho docente. No caso dos textos políticos dos organismos internacionais da região Iberoamericana, considero ainda escasso nosso debate como parte dessa região. Conhecer tais produções das políticas curriculares presentes nesses textos, permite-nos entender a constituição de demandas e os processos de articulação que se estabelecem entre elas na produção de um projeto hegemônico para a região, considerando as diferenças existentes entre os países. Por todas as razões apontadas, concordo com a UNESCO sobre a importância de investigarmos mais o papel e o impacto dos organismos internacionais e de cooperação multilateral nas políticas curriculares.

Operando com Laclau e Mouffe (2015) na desconstrução do discurso de que a docência é central para a qualidade da educação, devemos também considerar outras dimensões como concorrentes para que resultados exitosos sejam mais presentes na região Iberoamericana. O que significa que a centralidade da docência para a qualidade da educação não deve ser a única dimensão, e sim, uma delas, pois do modo como o discurso vem sendo produzido e articulado, as atribuições do professor ficam hipertrofiadas, gerando a responsabilização para o trabalho docente. $\mathrm{Na}$ articulação discursiva, o desempenho docente, nos textos políticos analisados, vem apoiada na garantia da educação de qualidade; no desenvolvimento profissional do magistério; no controle social da educação, na valorização e no reconhecimento do professor. Atrair melhores profissionais para a docência é uma demanda de amplo apoio social presente também na agenda coorporativa, mas as condições de trabalho e de carreira encontram-se associadas para que professores mais engajados, bem formados e envolvidos possam sentir-se motivados pela profissão.

Se a política de avaliação e controle baseada no desempenho do aluno trouxe muita ansiedade para o docente, conforme estudos de Oliva e Henson (1989), em decorrência da pressão pública exercida sobre o resultado de seu trabalho nas escolas, podemos entender que os 
processos de avaliação que têm sido praticados com os alunos e pretendem ser largamente utilizados na docência reeditam os problemas verificados no passado. As expectativas no desempenho docente, embora sejam difundidas nos textos políticos dos organismos internacionais, expressam diferentes vozes da sociedade que, insatisfeitas com o não atendimento de demandas caras aos mais diversos segmentos sociais, acabam por dirigir a crítica aos professores pelo insucesso dos alunos e da escola. O que podemos verificar na teoria curricular ao longo da sua história foi o desenvolvimento de experiências curriculares que, por vezes, voltam ressignificadas para o contexto contemporâneo da educação sem que diferentes grupos assumam a discussão crítica dos prós e contras que envolveram tais experiências.

A concepção de profissionalização docente esteve associada, desde os anos 1960, com as demandas de avaliação do processo de formação e atuação docente de modo semelhante à formação médica, como aponta Díaz-Barríga (1992). Mager; Beach (1976), defendiam também a correspondência entre a formação docente e médica ao afirmar que o professor "não pode cessar de aprimorar seus conhecimentos, do mesmo modo que o médico não para de aperfeiçoar suas habilidades médicas" (p.6). A analogia entre o processo de formação dessas duas profissões volta no cenário atual de debates sobre a docência e um exemplo disso pode ser percebido nos programas de residência docente. A despeito de todos os estudos voltados a buscar modelos do que vem a ser o professor eficaz/eficiente e das discussões sobre o modelo curricular de competências, em especial as experiências estadunidenses ocorridas nos anos 1960 e 1970, voltamos a nos ver, de certo modo, diante do confronto dessas perspectivas apresentado no atual debate que envolve a formulação de políticas de avaliação docente na região Iberoamericana.

Nesse processo de controle social, proposto nos textos políticos da OEI e UNESCO, podemos observar como fizeram Jones e Moore (1993), a atuação mais direta do Estado sobre a comunidade profissional docente na sua formação e trabalho como talvez não tenha sido projetado anteriormente a qualquer outra profissão. A autonomia que entendemos ser fundamental para o exercício do magistério, no âmbito de sua formação e prática profissional e a heterogeneidade que impede a cristalização de um perfil profissional, desafia a definição para fins de controle do que deve ser considerado conhecimento necessário, competência e prática adequada para as diferentes áreas de atuação.

Ainda que este trabalho empírico revele novas possibilidades de análise diante das diferentes dimensões que estão postas no debate sobre a avaliação docente, os discursos Iberoamericanos disseminados pela UNESCO e OEI, nas diferentes vozes que neles estão expressas, apontam para demandas que merecem ser mais aprofundadas e entendidas no complexo processo de produção das políticas curriculares.

\section{Referências}

ANTONIADES, A. Epistemic communities, epistemes and the construction of (world) politics. Global society, v. 17, n. 1, p. 21-38, 2003. DOI: 10.1080/0953732032000053980

BALL, S. J. Education reform: a critical and post-structural approach. Buckinghan: Open University, 1994.

BALL, S. J. Cidadania global, consumo e política educacional. In: SILVA, L. H. (Org.). A escola cidadã no contexto da globalização. Petrópolis: Vozes, 1998. p. 121-137. 
BALL, S.; BOWE, R. El currículum nacional y su "puesta en práctica": El papel de los departamentos de materias o asignaturas. Revista de Estudios de Currículum, v. 1, n. 2, p. 105-13, abr. 1998.

BERNSTEIN, B. Pedagogía, control simbólico e identidad. Madri: Morata, 1998.

DELORS, J. Educação: um tesouro a descobrir. Relatório da UNESCO. Brasília: MEC/UNESCO, 2001.

DIAS, R. E. Ciclo de políticas curriculares na formação de professores no Brasil (19962006). 2009. 248 f. Tese (Doutorado em Educação) - Faculdade de Educação, Universidade do Estado do Rio de Janeiro, Rio de Janeiro, 2009.

DIAS, R. E. Demandas das políticas curriculares para a formação de professores no espaço Ibero-americano. Revista E-Curriculum, São Paulo, v. 2, n.11, p. 461-478, ago. 2013.

DIAS, R. E; LOPES, A. C. Competências na formação de professores no Brasil: o que (não) há de novo. Educação \& Sociedade, Campinas, v. 24, n. 85, p. 1155-1177, set./dez. 2003. DOI: 10.1590/s0101-73302003000400004

DIAS, R. E.; LÓPEZ, S. B. Conhecimento, poder e interesse na produção de políticas curriculares. Currículo sem fronteiras, v. 6, n. 2, p. 53-66, jul./dez. 2006.

DÍAZ-BARRÍGA, A. Didactica y curriculum. 14. ed. México: Ediciones Nuevomar, 1992.

GIMENO SACRISTÁN, J. El profesor y la formación del profesorado. In: GIMENO

SACRISTÁN, J.; PÉREZ GOMEZ, A. La Enseñanza: su teoría y su práctica. Madrid: Akal, 1989. p. 349-355.

HYPOLITO, A. M. Reorganização gerencialista da escola e trabalho docente. Educação: Teoria e Prática, Rio Claro, v. 21, n. 38, p. 59-78, out./dez. 2011.

JONES, L.; MOORE, R. Education, competence, and the control of expertise. British Journal of the Sociology of Education, v. 14, n. 4, p.385-397, 1993. DOI: 10.1080/0142569930140403

LACLAU, E. Emancipación y diferencia. Buenos Aires: Difel, 1996.

LACLAU, E. La razón populista. Buenos Aires: Fondo de Cultura Econômica, 2005.

LACLAU, E.; MOUFFE, C. Hegemonia e estratégia socialista: por uma política democrática radical. Tradução de Joanildo Burity, Josias de Paula Jr. e Aécio Amaral. São Paulo: Intermeios, 2015.

LOPES, A. Competências na organização curricular da reforma do ensino médio. Boletim Técnico do SENAC, Rio de Janeiro, v. 27, n. 3, p. 1-20, 2001.

LOPES, A. C.; DIAS, R. E.; ABREU, R. G. de. Discursos nas políticas de currículo. Rio de Janeiro: Quartet, 2011.

LOPES, A. C.; MACEDO, E. Teorias de currículo. São Paulo: Cortez, 2011. 
MACEDO, E. Currículo e competência. In: LOPES, A.; MACEDO, E. Disciplinas e integração curricular: história e políticas. Rio de Janeiro: DP\&A, 2002. p. 115-143.

MAGER, R. F.; BEACH JR. K. M. O Planejamento do ensino profissional. Porto Alegre: Globo, 1976.

MOUFFE, C. O regresso do político. Tradução de Ana Cecília Simões. Lisboa: Gradiva, 1996.

OEI. Metas educativas 2021: la educación que queremos para la generación de los bicentenarios. Madrid: OEI, 2010.

OEI. Miradas sobre la educación en Iberoamérica. Madrid: OEI, 2011.

OEI. Miradas sobre la educación en Iberoamérica: desarrollo profesional docente y mejora de la educación. Madrid: OEI, 2013.

OLIVA, F.; HENSON, K. T. Cuales son las compentencias genéricas esenciales de la enseñanza? In: GIMENO SACRISTÁN, J.; PÉREZ GÓMEZ, A. La Enseñanza: su teoria y su práctica. Madrid: Akal, 1989. p. 357-363.

OLIVEIRA, D. A.; JORGE, T. A. da S. As políticas de avaliação, os docentes e a justiça escolar. Currículo sem fronteiras, v. 15, n. 2, p. 346-364, mai./ago. 2015.

POPKEWITZ, T. S. Reforma Educacional: uma nova política sociológica.Poder e Conhecimento em Educação. Porto Alegre: Artes Médicas, 1997.

UNESCO. Antecedentes y Criterios para la Elaboración de Políticas Docentes en América Latina y el Caribe: profesores para una educación para todos. Santiago de Chile: OREALC/ UNESCO, 2012. 